\title{
Low-temperature electrical resistivity and thermal conductivity of binary magnesium alloys
}

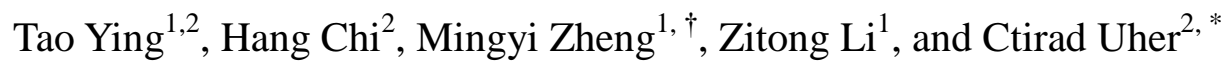

${ }^{1}$ Department of Materials Sciences and Engineering, Harbin Institute of Technology, Harbin, 150001, China

${ }^{2}$ Department of Physics, University of Michigan, Ann Arbor, Michigan 48109, USA

\section{Abstract:}

The electrical resistivity and thermal conductivity of some $\mathrm{Mg}-\mathrm{Al}, \mathrm{Mg}-\mathrm{Zn}$ and $\mathrm{Mg}-\mathrm{Mn}$ binary magnesium alloys were measured in the temperature range of $2-300$ K. The electrical resistivity increased with the increasing alloying content in each binary alloy system, while the thermal conductivity exhibited an opposite trend. The low-temperature thermal conductivity was understood using $\kappa=\left(A / T+B T^{2}\right)^{-1}+C T^{2}$, which is found to be applicable in various binary and/or multi-component alloy systems. The parameters $A, B$, and $C$ were determined through numerical fitting of the experimental data. Significant differences were found in the effect of three solute atoms on the thermal conductivity of $\mathrm{Mg}$. The reasons for large differences in the thermal conductivity of the three binary magnesium alloy systems are discussed. Variations in the atomic volume and the valence are believed to play an important role on the thermal conductivity of magnesium alloys.

Key words: Electrical resistivity, thermal conductivity, binary magnesium alloys

*Corresponding Author. Tel. +1 (734) 764-3933; E-mail address: cuher@umich.edu

${ }^{\dagger}$ Corresponding Author. Tel. +86 45186402291; E-mail address: zhenghe@ hit.edu.cn 


\section{Introduction}

Magnesium alloys, owing to their low density, high specific strength, and excellent damping capacity, are usually used as lightweight structural materials in various applications, such as automobile parts and electrical appliances [1, 2]. From an economic point of view, magnesium alloys play a very important role in reducing the overall weight of the product, as they are much lighter than steel and approximately one-third lighter than aluminium for a given volume. Recently, their good ability to conduct and spread the heat has also attracted considerable attention for potential cryogenic and aerospace applications [3, 4].

However, the information concerning thermophysical properties of magnesium alloys such as thermal conductivity is rather limited, especially at low temperatures. Even though the interest in the thermal conductivity of magnesium dates back to the late 1930's, most of the work so far has focused on pure magnesium [5, 6] and magnesium alloys above room temperature [7, 8]. Only more recently has the behaviour of thermal conductivity at low temperatures attracted attention of the scientific and engineering communities. In particular, Galeazzi et al. [4] measured the thermal conductivity of pure magnesium in the $60-150 \mathrm{mK}$ temperature range, and the results indicate that magnesium can serve as a lightweight alternative to copper for the fabrication of refrigerator components for space. Lee et al. [9] investigated the thermal conductivity of two Mg-Al-Zn alloys, AZ31 (Al 3wt\% and $\mathrm{Zn} \mathrm{1wt \% )} \mathrm{and}$ $\mathrm{AZ61}(\mathrm{Al} 6 \mathrm{wt} \%$ and $\mathrm{Zn} 1 \mathrm{wt} \%$ ), in the temperature range of $150-673 \mathrm{~K}$ and the results show that the thermal conductivity increase with temperature in both alloys, 
and that the experimental data can be useful in thermal design for automobiles and notebook applications. In order to explore the application potential of magnesium alloys at low temperatures, it is essential to analyze the effect of individual alloying elements on the thermal conductivity, so as to provide guidance in choosing suitable magnesium alloy systems for various applications.

Therefore, in this paper, the thermal conductivity of three most commonly-used binary magnesium alloy systems, $\mathrm{Mg}-\mathrm{Al}, \mathrm{Mg}-\mathrm{Zn}$ and $\mathrm{Mg}-\mathrm{Mn}$, have been investigated in the temperature range of $2-300 \mathrm{~K}$. Because the electrical resistivity is closely related to the electronic part of thermal conductivity, the electrical resistivity measurements were conducted at the same time.

\section{Experimental}

Three binary magnesium alloys containing Al, Zn and Mn solutes were prepared by permanent mold casting in a $\mathrm{CO}_{2} / \mathrm{SF}_{6}$ protective atmosphere. The composition of all alloys was analyzed by the AXIOS-PW4400 X-ray fluorescence spectrometer. The nominal and actual compositions of the alloys are listed in Table 1. Overall, the agreement between the nominal and the actual alloy concentrations is very good. Samples with dimensions of $0.5 \mathrm{~mm} \times 1.5 \mathrm{~mm} \times 12 \mathrm{~mm}$ were cut from the ingots for the low temperature electrical resistivity and thermal conductivity measurements. Low-temperature transport property measurements were carried out over the temperature range of $2-300 \mathrm{~K}$. Electrical resistivity and thermal conductivity were determined using a longitudinal steady-state technique in a home-made cryostat. 
Thermal gradients were measured by fine Chromel-Au/Fe thermocouples, with a small strain gauge serving as a heater. Electrical resistivity was measured by inputting a current along the length of the sample and collecting the voltage signal using a 2182A Keithley nanovoltmeter. Detailed description of the low-temperature apparatus can be found elsewhere $[10,11]$. The low temperature transport properties of pure magnesium were also measured under the same conditions for comparison. The uncertainties of electrical resistivity and thermal conductivity are estimated to be $\pm 3 \%$ and $\pm 5 \%$, respectively.

\section{Results}

\subsection{Electrical resistivity}

The temperature dependence of the electrical resistivity of pure $\mathrm{Mg}$ and binary $\mathrm{Mg}-\mathrm{Al}$ alloys is shown in Fig. 1. As Fig. 1(a) indicates, no resistance maximum or minimum is found at low temperatures and the electrical resistivity of all four samples is little temperature dependent in the temperature range $2-40 \mathrm{~K}$. However, as the temperature increases further, the electrical resistivity increases sharply due to enhanced electron-phonon scattering as indicated by the data in Fig. 1(b). As expected, pure $\mathrm{Mg}$ has the lowest value of the electrical resistivity. With the increasing content of $\mathrm{Al}$, the electrical resistivity increases due to stronger alloy scattering even though Al has a much larger electrical conductivity than $\mathrm{Mg}$.

Figure 2 shows the temperature dependence of the electrical resistivity of binary $\mathrm{Mg}-\mathrm{Zn}$ alloys. In general, the behavior of the electrical resistivity is similar to that of 
$\mathrm{Mg}-\mathrm{Al}$ alloys. However, it is worth noting that the $\mathrm{Zn}$ impurity has a much weaker effect on the electrical resistivity than does Al. For instance, the resistivity of $\mathrm{Mg}-0.5 \% \mathrm{Zn}$ alloy is only about one-half that of the $\mathrm{Mg}-0.5 \% \mathrm{Al}$ alloy and even $5 \mathrm{wt} \%$ of $\mathrm{Zn}$ results in lower resistivity than $1 \mathrm{wt} \%$ of $\mathrm{Al}$.

In Fig. 3, the temperature-dependent resistivity of binary $\mathrm{Mg}-\mathrm{Mn}$ alloys is displayed. Unlike the $\mathrm{Mg}-\mathrm{Al}$ and $\mathrm{Mg}-\mathrm{Zn}$ alloy systems, $\mathrm{Mg}-\mathrm{Mn}$ alloys exhibit a resistivity minimum at $T_{\min }$, as is easily discerned at low temperatures in both Figs. 3(a) and 3(b). This phenomenon is related to magnetic scattering often referred to as the Kondo effect $[12,13]$. As the concentration of impurity $c$ increases, $T_{\min }$ seems to follow the classical $c^{1 / 5}$ dependence, as indicated in the inset of Fig. 3 (b).

\subsection{Thermal conductivity}

Figure 4 shows the temperature dependence of the thermal conductivity of $\mathrm{Mg}-\mathrm{Al}$ alloys and of pure $\mathrm{Mg}$ in the temperature range $2-300 \mathrm{~K}$. In pure $\mathrm{Mg}$, the thermal conductivity curve displays a pronounced peak in the range of $20-30 \mathrm{~K}$, reaching values greater than $700 \mathrm{~W} / \mathrm{m}-\mathrm{K}$. This is a characteristic behavior of a pure metallic element. Compared to pure $\mathrm{Mg}$, no obvious peaks are found at low temperatures in binary $\mathrm{Mg}-\mathrm{Al}$ alloys and the thermal conductivity increases monotonically with temperature. Although thermal conductivity decreases with increasing content of $\mathrm{Al}$, the difference in the magnitude of the thermal conductivity of pure $\mathrm{Mg}$ and $\mathrm{Mg}-\mathrm{Al}$ alloys becomes smaller and smaller as the temperature approaches room temperature.

The temperature dependence of thermal conductivity of $\mathrm{Mg}-\mathrm{Zn}$ alloys is shown in 
Fig. 5. The two lowest content alloys, $\mathrm{Mg}-0.5 \% \mathrm{Zn}$ and $\mathrm{Mg}-1.5 \% \mathrm{Zn}$, exhibit a thermal conductivity maximum in the temperature range $30-40 \mathrm{~K}$, but the peak is significantly reduced at higher $\mathrm{Zn}$ concentrations. The presence of the low temperature peak for concentrations of $\mathrm{Zn}$ up to $1.5 \mathrm{wt} \%$ attests to a weaker scattering power of $\mathrm{Zn}$ in comparison to $\mathrm{Al}$, just as was the case of the electrical resistivity.

The variation of thermal conductivity with temperature in binary $\mathrm{Mg}-\mathrm{Mn}$ alloys is shown in Fig. 6. The trend is analogous to that of $\mathrm{Mg}-\mathrm{Al}$ alloys with no distinct peaks observed at low temperatures, a substantially monotonic temperature dependence, and comparable values of thermal conductivity for comparably dilute alloys.

\section{Discussion}

\subsection{Electrical resistivity}

According to the Matthiessen's rule [14], the total electrical resistivity $\rho$ of pure metals and alloys consists of two independent parts: the residual resistivity $\rho_{0}$ caused by scattering of electrons by impurities and structural imperfections, and the ideal resistivity $\rho_{i}$ governed by scattering of charge carriers by phonons, i.e.,

$$
\rho=\rho_{0}+\rho_{i}
$$

The residual resistivity $\rho_{0}$ is independent of temperature, and, under most experimental conditions, the electrical resistivity of metals arising from structural imperfections, e.g., dislocations and grain boundaries, is small compared with that produced by phonons and solute atoms [15]. The ideal resistivity $\rho_{i}$ is temperature dependent. Temperature coefficients of various samples are listed in Table 2. The 
Matthiessen's rule states that the temperature coefficient is independent of concentration, however, the temperature coefficient of the resistivity obtained in this paper is not a constant. Salkovitz et al. [16] also observed such a deviation from Matthiessen's rule in the work on dilute binary magnesium alloys, including $\mathrm{Mg}-\mathrm{Al}$, $\mathrm{Mg}-\mathrm{Ag}$ and $\mathrm{Mg}-\mathrm{In}$. The reason is that $\rho_{i}$ is, in fact, dependent upon the axes ratio $c / a$ and upon the Brillouin zone overlap [17]. Because the ratio cla and the degree of zone overlap change with concentration, this imposes the dependence of $\rho_{i}$ on the concentration.

The resistivity increment due to three types of solute elements was determined and is shown as a function of composition in Fig. 7. The quantity $\Delta \rho$ is the resistivity increment due to the presence of solute atoms defined as

$\Delta \rho_{0}=\rho_{0 \text { (alloy) }}-\rho_{0}(\mathrm{Mg})$

where $\rho_{0}$ was determined by the value of the electrical resistivity at $5 \mathrm{~K}$. Figure 7 is a quantitative representation of our earlier statements that $\mathrm{Al}$ and $\mathrm{Mn}$ impurities in $\mathrm{Mg}$ cause a much stronger scattering than $\mathrm{Zn}$. Moreover, the data indicate that the electrical resistivity increases linearly when the concentration of solute atoms is low. $0.5 \mathrm{at} \% \mathrm{Mn}, \mathrm{Al}$ and $\mathrm{Zn}$ dissolved in pure $\mathrm{Mg}$ increase the electrical resistivity by about $22 \mathrm{n} \Omega-\mathrm{m}, 10 \mathrm{n} \Omega-\mathrm{m}$, and $5 \mathrm{n} \Omega-\mathrm{m}$, respectively.

\subsection{Thermal conductivity}

In a conductor, the total thermal conductivity $\kappa$ is generally expressed as [14]:

$\kappa=\kappa_{e}+\kappa_{L}$ 
where the electronic component $\kappa_{e}$ dominates in the case of pure metals, and the lattice component $\kappa_{L}$ becomes relatively more significant in alloys.

As is well known, the electrical conduction and thermal conduction are closely related via the Wiedemann-Franz law of the form [14]

$\kappa_{e}=L_{0} \sigma T$

where $\sigma$ is the electrical conductivity and $L_{0}$ is the Lorenz constant $\left(2.45 \times 10^{-8}{\mathrm{~W} \Omega \mathrm{K}^{-2}}^{-2}\right.$ for highly degenerate systems such as metals). The Wiedemann-Franz law is essentially always used [18,19] to calculate the electronic part of thermal conductivity from the measured electrical conductivity.

However, the validity of such approach requires two conditions [15]: (1) the electron gas is highly degenerate, which is almost always satisfied in metals and their dilute alloys; and (2) the relaxation time (or, alternatively, the mean-free path) of electrons in electrical and thermal processes is the same, which depends on the nature of the scattering process. If the scattering process is elastic, the relaxation times are identical. However, if the nature of scattering has an inelastic character, the relaxation times can be substantially different between electrical and thermal transport, see, e.g., [14]. The important scattering processes concerning the electrical and thermal conductions by electrons are: (1) the elastic scattering of electrons by static imperfections [20], and (2) scattering of electrons by phonons, a process that has an inelastic character. At the lowest temperatures, impurity scattering dominates and provides a sufficiently large change in electron wave-vector so that it is equally effective in relaxing out-of equilibrium distributions created by the electric field and 
the thermal gradient. Thus the two relaxation times are identical and the Wiedemann-Franz law is obeyed. At temperatures somewhat above the ambient, the dominant phonons have large wave-vectors and Umklapp processes are equally capable of restoring equilibrium in systems disturbed by electric fields and thermal gradients, hence, again, the relaxation times for electrical and thermal processes tend to be identical and the Wiedemann-Franz law holds. However, at temperatures somewhat below ambient $\left(T<\Theta_{D}\right)$, the phonon wave-vector is not large enough to cause, in a single collision with an electron, a large enough change in the electron wave-vector to give rise to electrical resistance, while it is perfectly capable, in a single collision, to cause thermal resistance merely by lifting an electron from below the Fermi energy to an empty state just above the Fermi energy. In this situation, the relaxation times for electrical and thermal processes might differ substantially and this is indicated by a significantly decreasing value of the Lorenz number. In this case, the use of Wiedemann-Franz law is inappropriate and would cause a significant overestimate of the electronic thermal conductivity.

Using the Matthiessen's rule, for temperatures below about $\theta_{D} / 5$ (the Debye temperature $\theta_{D}$ of magnesium is $320 \mathrm{~K}$ ), the electronic thermal conductivity $\kappa_{e}$ is usually given by [21]

$1 / \kappa_{e}=A / T+B T^{n}$

where the first term on the right side of the equation represents the electron-impurity scattering and the second term comes from the electron-phonon scattering, and $n=2$ for magnesium [6]. 
The lattice thermal conductivity $\kappa_{L}$ is mainly limited by phonon-impurity scattering at low temperatures and is given by [22],

$\kappa_{L}=C T^{2}$

Thus, combining Eq. 3, Eq. 5, and Eq. 6, the total thermal conductivity $\kappa$ of magnesium alloys can be expressed as

$\kappa=\left(A / T+B T^{2}\right)^{-1}+C T^{2}$

where coefficients $A, B$, and $C$ can be obtained through numerical fitting of the experimental data. Figures $8-10$ display the fitting results which are in excellent agreement with the experimental data in a wide temperature range of $2-100 \mathrm{~K}$. The coefficients $A, B$, and $C$ are summarized in Table 3. The increasing trend of $A$ for all the alloy systems reflects very well the enhanced electron-impurity scattering as the content of solute increases. The generally decreasing trend of $C$ for all the alloy systems also indicates a stronger phonon-impurity scattering with more defects being introduced.

The parameter $B$ in Eq. 7 is given by Sondheimer [23] as

$$
B=D W_{\infty} N^{2 / 3} / \Theta_{D}^{2}
$$

where $D$ is a constant having a value of 71.7 according to Sondheimer, $\mathrm{N}$ is the effective number of free electrons per atom, and $W_{\infty}$ is the limiting value of the ideal thermal resistivity at high temperatures (using $300 \mathrm{~K}$ experimental value). The value of $N^{2 / 3}=0.21$ obtained from Eq. 8 for pure $\mathrm{Mg}$ is in good agreement with the value of 0.22 obtained in Ref. 6 .

In addition, it is worth noting that Eq. 7 is not only useful to predict the thermal 
conductivity of binary magnesium alloys studied in this paper, but it is also applicable to the low-temperature thermal conductivity of other metal alloy systems, such as the aluminum and copper alloys shown in Fig. 11. The fitting parameters are given in Table 4 . The fitting result agrees with the experimental data very well in all binary or multi-component alloys tabulated in Ref. 24.

Clearly, the type of impurity added to $\mathrm{Mg}$ does matter. Since the thermal conductivity is sensitive to the microstructure, the lattice distortion caused by different kinds of solute atoms can affect the value of thermal conductivity to a different degree. The lattice distortion may be regarded as the sum of two effects [25]: (1) One arising from the difference in atomic volumes of the solute and magnesium, which may lead to local lattice expansion or contraction, depending on whether the impurity has a larger or smaller atomic volume than magnesium.

(2) The other effect is due to the difference in valence of a solute and magnesium such that the valence of the solute greater than 2 introduces a tendency towards lattice expansion and vice versa. This effect is closely related to the electronic structure of magnesium and the shape of the Brillouin zone [25]. Therefore, we provide some information about atomic volumes and valences of alloying elements in Table 5. Comparing the atomic volumes of the three alloying elements with that of magnesium, we note that $\mathrm{Mn}$ has the most unfavorable size and thermal conductivity of $\mathrm{Mg}-\mathrm{Mn}$ alloys is, indeed, the lowest, particularly at low temperatures where impurity scattering dominates. The electrical resistivity in Fig. 7 also attests to the fact that $\mathrm{Mn}$ creates the greatest distortion in the $\mathrm{Mg}$ lattice and the incremental resistivity is the 
largest of the three impurities. Although $\mathrm{Zn}$ creates a greater distortion in the $\mathrm{Mg}$ lattice than does $\mathrm{Al}$, its valence is identical to $\mathrm{Mg}$ and thus disturbs the band structure to a lesser extent. Adding $\mathrm{Zn}$ to $\mathrm{Mg}$ does not change the number of electrons per atom and the shape of the Brillouin zone is unchanged. In contrast, Al with its valence of 3 increases the number of electrons and, in fact, activates the zone overlap and causes lattice distortions and, hence, lowers the thermal conductivity.

\section{Conclusions}

The electrical resistivity and thermal conductivity of pure $\mathrm{Mg}$ and dilute binary $\mathrm{Mg}-\mathrm{Al}, \mathrm{Mg}-\mathrm{Zn}$ and $\mathrm{Mg}-\mathrm{Mn}$ magnesium alloys were measured over the temperature range $2-300 \mathrm{~K}$. The following conclusions can be drawn:

(1) Electrical resistivity increases with the increasing impurity content in each magnesium alloy system. The electrical resistivity of $\mathrm{Mg}-\mathrm{Al}$ and $\mathrm{Mg}-\mathrm{Zn}$ alloys is monotonically increasing while the electrical resistivity of $\mathrm{Mg}-\mathrm{Mn}$ alloys shows a distinct minimum at low temperatures. Among the three alloying elements, Mn tends to induce the largest increment of residual resistivity, while $\mathrm{Zn}$ is the weakest electron scatterer.

(2) Thermal conductivity of pure $\mathrm{Mg}, \mathrm{Mg}-0.5 \% \mathrm{Zn}$ and $\mathrm{Mg}-1.5 \% \mathrm{Zn}$ alloys exhibited peaks in the temperature range $20-40 \mathrm{~K}$, while no obvious peaks were found in $\mathrm{Mg}-\mathrm{Al}$ and $\mathrm{Mg}-\mathrm{Mn}$ alloys. The thermal conductivity of $\mathrm{Mg}-\mathrm{Al}$ and $\mathrm{Mg}-\mathrm{Mn}$ alloys increased monotonically with temperature.

(3) Thermal conductivity of pure $\mathrm{Mg}$ and binary magnesium alloys was fitted to an 
equation of $\kappa=\left(A / T+B T^{2}\right)^{-1}+C T^{2}$ in the temperature range $2-100 \mathrm{~K}$ and the parameters $\mathrm{A}, \mathrm{B}$, and $\mathrm{C}$ were determined. The value of parameters for pure $\mathrm{Mg}$ agrees well with the values previously established. The equation is also applicable for predicting the low-temperature thermal conductivity of other alloy systems such as aluminum and copper alloys.

(4) In binary magnesium alloys, different alloying elements exert different influence on the thermal conductivity. This is due to different volumes and different valences of solute and $\mathrm{Mg}$ atoms.

\section{Acknowledgements}

Experimental transport studies were conducted at the University of Michigan with the support of the Center for Solar and Thermal Energy Conversion, an Energy Frontier Research Center funded by the U.S. Department of Energy, Office of Science, Office of Basic Energy Sciences under Award No. DE-SC0000957. The authors gratefully acknowledge the financial support from the Major Program for the Application Research and Development of Heilongjiang Province, China, the Ph. D joint training program of Harbin Institute of Technology, and the Chinese Scholarship Council.

\section{References}

[1] Kulekci KM. Int J Adv Manuf Technol 2008;39:851.

[2] Mordik BL, Ebert T. Mater Sci Eng A 2001;302:37.

[3] Ostrovsky I, Henn Y. International Conference "NEW CHALLENGES IN AERONAUTICS” ASTEC'07, August 19-22, Moscow, (2007). 
[4] Galeazzi M, Bogorin DF, Prasai K, Uprety Y, McCammon D. Rev Sci Instrum 2010;81:076105.

[5] Ho CY, Powell RW, Liley PE. J Phys Chem Ref 1972;1:279.

[6] Kemp WRG, Sreedhar AK, White GK. Proc Phys Soc A 1953;66:1077.

[7] Yamasaki M, Kawamura Y. Scripta Mater 2009;60:264

[8] Rudajevová A, Buch FV, Mordike BL. J Alloys Compd 1999;292:27-30.

[9] Lee S, Ham HJ, Kwon SY, Kim SW, Suh CM. Int J Thermophys 2013;34(12): 2343.

[10] Chi H, Chen C, Phillips JD, Uher C. Appl Phys Lett 2013;103:042108.

[11] Chi H, Liu W, Sun K, Su X, Wang G, Lošt'ák , Kucek V, Drašar Č, Uher C. Phys Rev B 2013;88:045202.

[12] Kondo J. Prog. Theor Phys 1964;32:1.

[13] Hedgcock FT, Rizzuto C. Phys Rev 1967;163:517.

[14] Berman B. Thermal conduction in solids, Oxford: Clarendon Press; 1976.

[15] Kumar GS, Prasad G, Pohl RO. J Mater Sci 1993;28:4261

[16] Salkovitz EI, Schindler AI, Kammer EW. Phys Rev 1957;105:887

[17] Schindler AI, Salkovitz EI. Phys Rev 1953;91:1320

[18] Berman B, MacDonald DKC. Proc R Soc Lond A 1952;211:122.

[19] White GK. Aust J Phys 1953;6:397.

[20] Uher C. Thermal conductivity of metals, in: Tritt TM (Eds.). Thermal conductivity-Theory, Properties and Applications. New York: Kluwer Academic /Plenum Publishers; 2004. 
[21] White GK, Woods SB. Can J Phys 1954;33:58.

[22] Powell RL, Roder HM, Rogers WM. J Appl Phys 1957;28:1282

[23] Sondheimer EH. Proc Roy Soc A 1950;203:75.

[24] Touloukian YS, Powell RW, Ho CY, Klemens PG. Thermophysical Properties of Matter, Vol. 1, New York: Plenum; 1970.

[25] Raynor GV. The Physical Metallurgy of Magnesium and Its Alloys, London: Pergamon Press; 1959. 
Table 1 The nominal and actual compositions of the binary magnesium alloys

\begin{tabular}{ccc}
\hline $\begin{array}{c}\text { Nominal } \\
\text { composition of alloy }\end{array}$ & $\begin{array}{c}\text { Actual chemical } \\
\text { composition }\end{array}$ & $\begin{array}{c}\text { Actual chemical } \\
\text { composition }\end{array}$ \\
\hline $\mathrm{Mg}-0.5 \% \mathrm{Al}$ & 0.58 & $(\mathrm{at} \%)$ \\
$\mathrm{Mg}-1.0 \% \mathrm{Al}$ & 1.25 & 0.52 \\
$\mathrm{Mg}-1.5 \% \mathrm{Al}$ & 1.88 & 1.11 \\
$\mathrm{Mg}-0.5 \% \mathrm{Zn}$ & 0.51 & 1.67 \\
$\mathrm{Mg}-1.5 \% \mathrm{Zn}$ & 1.49 & 0.19 \\
$\mathrm{Mg}-2.5 \% \mathrm{Zn}$ & 2.59 & 0.55 \\
$\mathrm{Mg}-4.0 \% \mathrm{Zn}$ & 4.05 & 0.97 \\
$\mathrm{Mg}-5.0 \% \mathrm{Zn}$ & 5.20 & 1.50 \\
$\mathrm{Mg}-0.5 \% \mathrm{Mn}$ & 0.49 & 1.92 \\
$\mathrm{Mg}-1.0 \% \mathrm{Mn}$ & 0.93 & 0.22 \\
$\mathrm{Mg}-1.5 \% \mathrm{Mn}$ & 1.47 & 0.41 \\
\hline
\end{tabular}


Table 2 Temperature coefficient of electrical resistivity for binary magnesium alloys

\begin{tabular}{cc}
\hline Materials & $\begin{array}{r}\text { Temperature coefficient } \\
(\mu \Omega-\mathrm{m} / \mathrm{K})\end{array}$ \\
\hline Pure $\mathrm{Mg}$ & 1.63 \\
$\mathrm{Mg}-0.5 \% \mathrm{Al}$ & 1.99 \\
$\mathrm{Mg}-1.0 \% \mathrm{Al}$ & 1.92 \\
$\mathrm{Mg}-1.5 \% \mathrm{Al}$ & 1.98 \\
$\mathrm{Mg}-0.5 \% \mathrm{Zn}$ & 1.84 \\
$\mathrm{Mg}-1.5 \% \mathrm{Zn}$ & 2.33 \\
$\mathrm{Mg}-2.5 \% \mathrm{Zn}$ & 1.67 \\
$\mathrm{Mg}-4.0 \% \mathrm{Zn}$ & 1.56 \\
$\mathrm{Mg}-5.0 \% \mathrm{Zn}$ & 1.89 \\
$\mathrm{Mg}-0.5 \% \mathrm{Mn}$ & 1.98 \\
$\mathrm{Mg}-1.0 \% \mathrm{Mn}$ & 1.60 \\
$\mathrm{Mg}-1.5 \% \mathrm{Mn}$ & 1.64 \\
\hline
\end{tabular}


Table 3 Summary of the coefficients of $A, B$, and $C$ for binary magnesium alloys

\begin{tabular}{cccc}
\hline Materials & $A\left(\mathrm{~m}-\mathrm{K}^{2} / \mathrm{W}\right)$ & $B\left(10^{-6} \mathrm{~m} / \mathrm{W}-\mathrm{K}\right)$ & $C\left(10^{-3} \mathrm{~W} / \mathrm{m}-\mathrm{K}^{3}\right)$ \\
\hline Pure Mg & 0.020 & 0.96 & - \\
$\mathrm{Mg}-0.5 \% \mathrm{Al}$ & 0.351 & 1.71 & 5.86 \\
$\mathrm{Mg}-1.0 \% \mathrm{Al}$ & 0.593 & 2.92 & 5.38 \\
$\mathrm{Mg}-1.5 \% \mathrm{Al}$ & 0.912 & 2.93 & 4.08 \\
$\mathrm{Mg}-0.5 \% \mathrm{Zn}$ & 0.124 & 1.50 & 7.76 \\
$\mathrm{Mg}-1.5 \% \mathrm{Zn}$ & 0.181 & 1.77 & 6.92 \\
$\mathrm{Mg}-2.5 \% \mathrm{Zn}$ & 0.324 & 2.12 & 6.47 \\
$\mathrm{Mg}-4.0 \% \mathrm{Zn}$ & 0.451 & 2.49 & 5.86 \\
$\mathrm{Mg}-5.0 \% \mathrm{Zn}$ & 0.569 & 2.84 & 5.42 \\
$\mathrm{Mg}-0.5 \% \mathrm{Mn}$ & 0.390 & 1.57 & 5.50 \\
$\mathrm{Mg}-1.0 \% \mathrm{Mn}$ & 0.887 & 2.33 & 3.94 \\
$\mathrm{Mg}-1.5 \% \mathrm{Mn}$ & 1.112 & 2.66 & 3.97 \\
\hline
\end{tabular}


Table 4 Summary of the coefficients of $A, B$, and $C$ for aluminum and copper alloys

\begin{tabular}{lccc}
\hline Materials & $A\left(\mathrm{~m}-\mathrm{K}^{2} / \mathrm{W}\right)$ & $B\left(10^{-7} \mathrm{~m} / \mathrm{W}-\mathrm{K}\right)$ & $C\left(10^{-3} \mathrm{~W} / \mathrm{m}-\mathrm{K}^{3}\right)$ \\
\hline $5052 \mathrm{Al}$ alloy & 0.890 & 6.84 & 2.51 \\
$5154 \mathrm{Al}$ alloy & 0.965 & 0.89 & 1.13 \\
Cu-As alloy & 0.605 & 29.9 & 7.84 \\
Cu-Be alloy & 2.081 & 39.3 & 2.75 \\
Al-Cu-Mg alloy & 0.627 & 5.59 & 0.15 \\
Al-Fe-Si alloy & 0.086 & 5.77 & 7.22 \\
6063 Al alloy & 0.116 & 6.14 & 7.36 \\
5052-O Al alloy & 0.839 & 11.8 & 3.62 \\
5154-O Al alloy & 0.967 & 15.2 & 3.80 \\
5083-O Al alloy & 1.296 & 18.0 & 2.89 \\
3003-F Al alloy & 0.364 & 8.59 & 5.84 \\
7075 Al alloy & 1.092 & 1.52 & 3.53 \\
\hline
\end{tabular}

Table 5 Some basic information of various alloying elements in magnesium

\begin{tabular}{lcc}
\hline Alloying element & Valence & $\Delta \mathrm{V} / \mathrm{V}_{\mathrm{Mg}} *(\%)$ \\
\hline $\mathrm{Al}$ & 3 & -28.4 \\
$\mathrm{Zn}$ & 2 & -34.5 \\
$\mathrm{Mn}$ & $2(7)$ & -47.1 \\
\hline
\end{tabular}

* Atomic volume relative to magnesium 

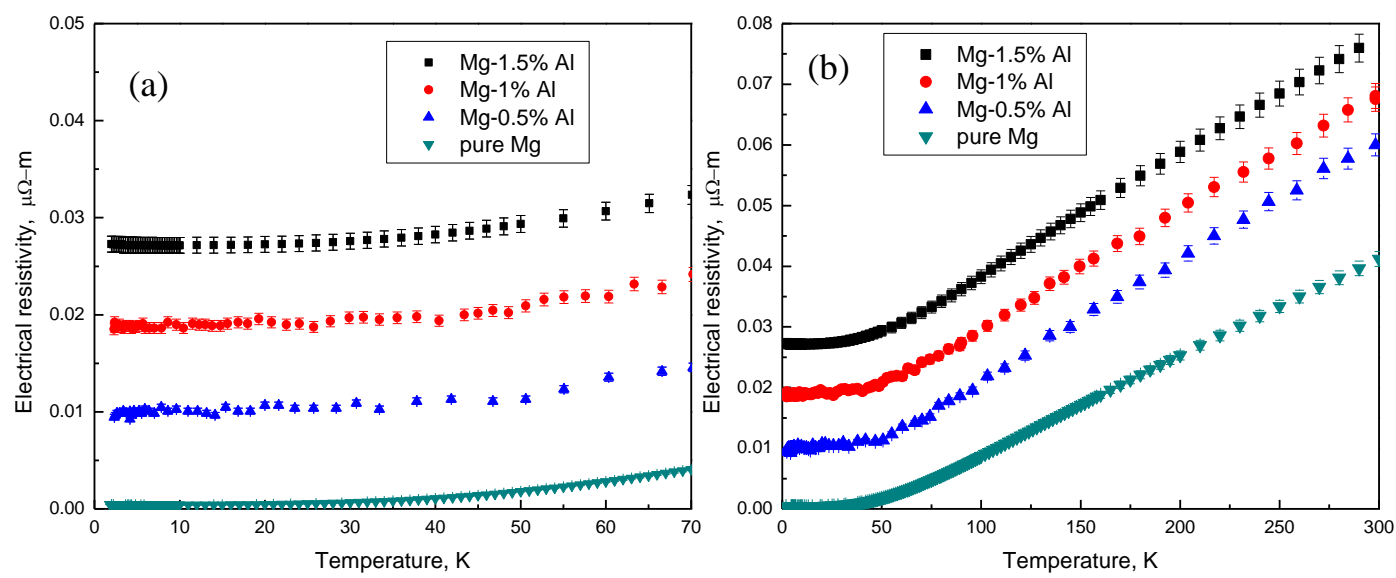

Figure 1: Temperature dependent electrical resistivity of $\mathrm{Mg}-\mathrm{Al}$ alloys and of pure $\mathrm{Mg}$ in the temperature range of (a) $2-70 \mathrm{~K}$ and (b) $2-300 \mathrm{~K}$.
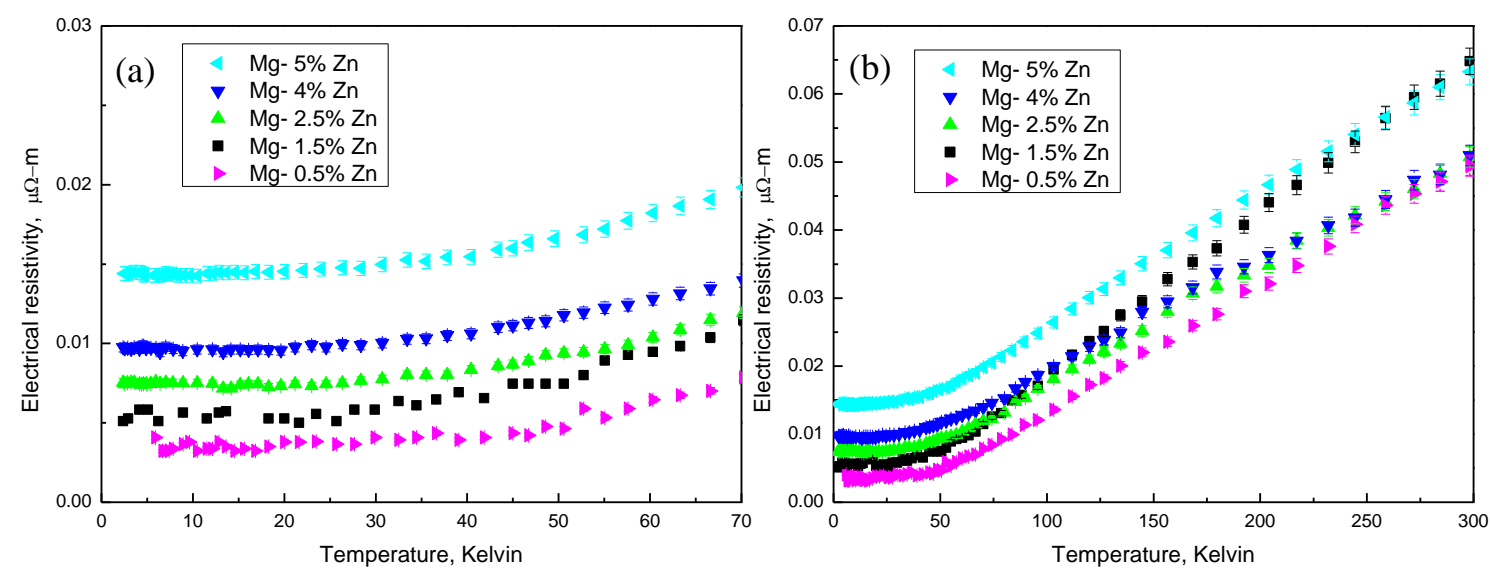

Figure 2: Temperature dependent electrical resistivity of $\mathrm{Mg}-\mathrm{Zn}$ alloys in the temperature range of (a) $2-70 \mathrm{~K}$ and (b) $2-300 \mathrm{~K}$. 

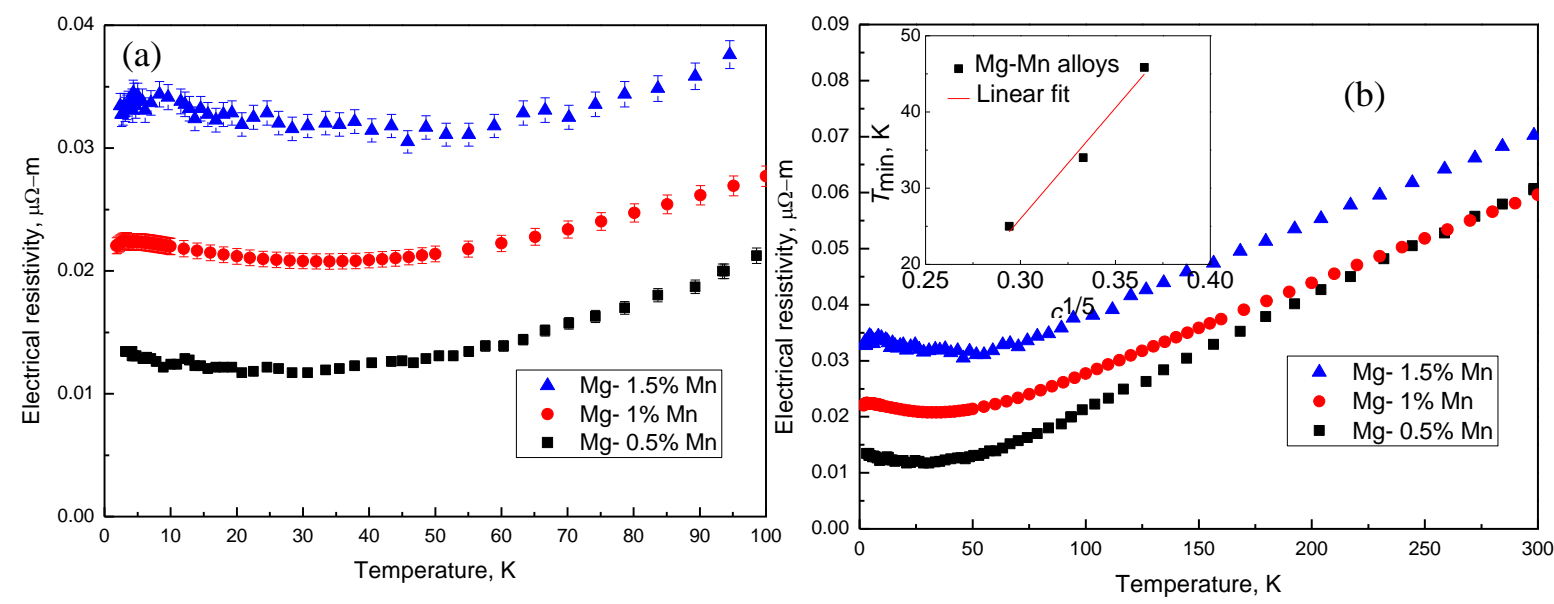

Figure 3: Temperature dependent electrical resistivity of $\mathrm{Mg}-\mathrm{Mn}$ alloys in the temperature range of (a) $2-100 \mathrm{~K}$ and (b) $2-300 \mathrm{~K}$. Inset: $T_{\min }$ versus $c^{1 / 5}$ of $\mathrm{Mg}-\mathrm{Mn}$ alloys. Note a distinct minimum in the electrical resistivity curves that shifts to higher temperatures with increasing content of solute.

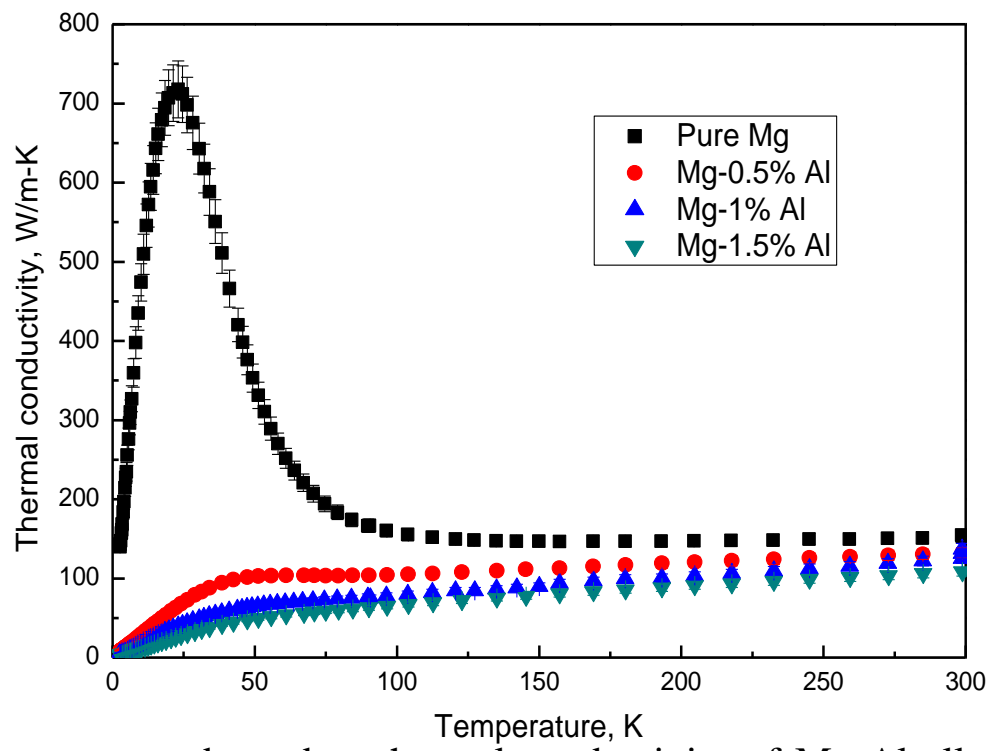

Figure 4: Temperature dependent thermal conductivity of $\mathrm{Mg}-\mathrm{Al}$ alloys and of pure Mg. 


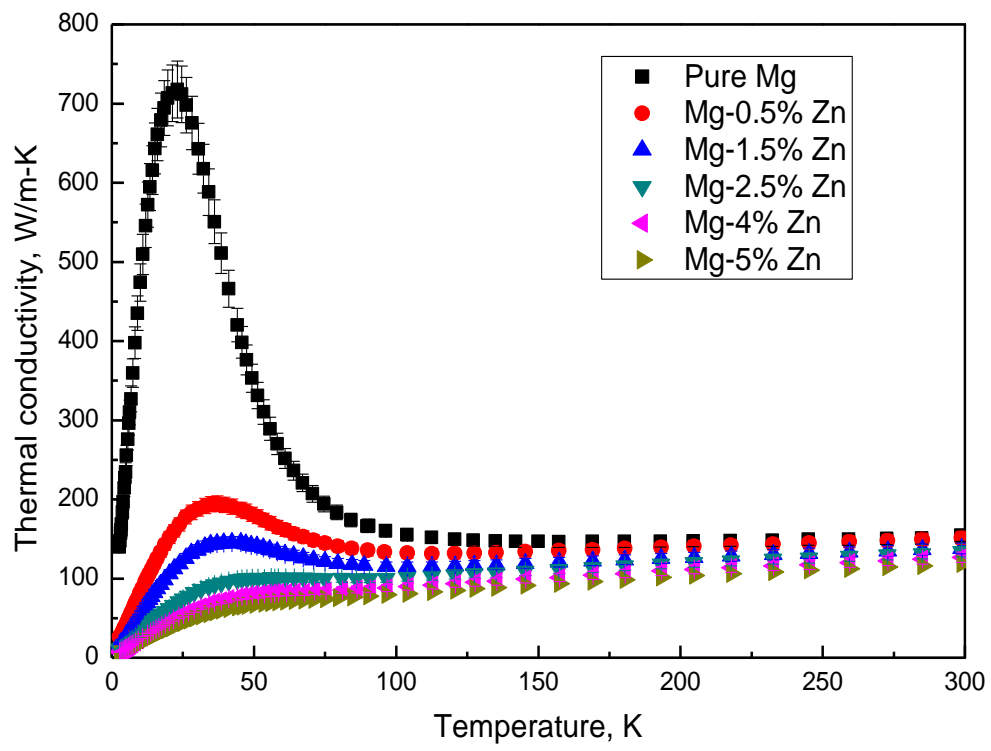

Figure 5: Temperature dependent thermal conductivity of $\mathrm{Mg}-\mathrm{Zn}$ alloys.

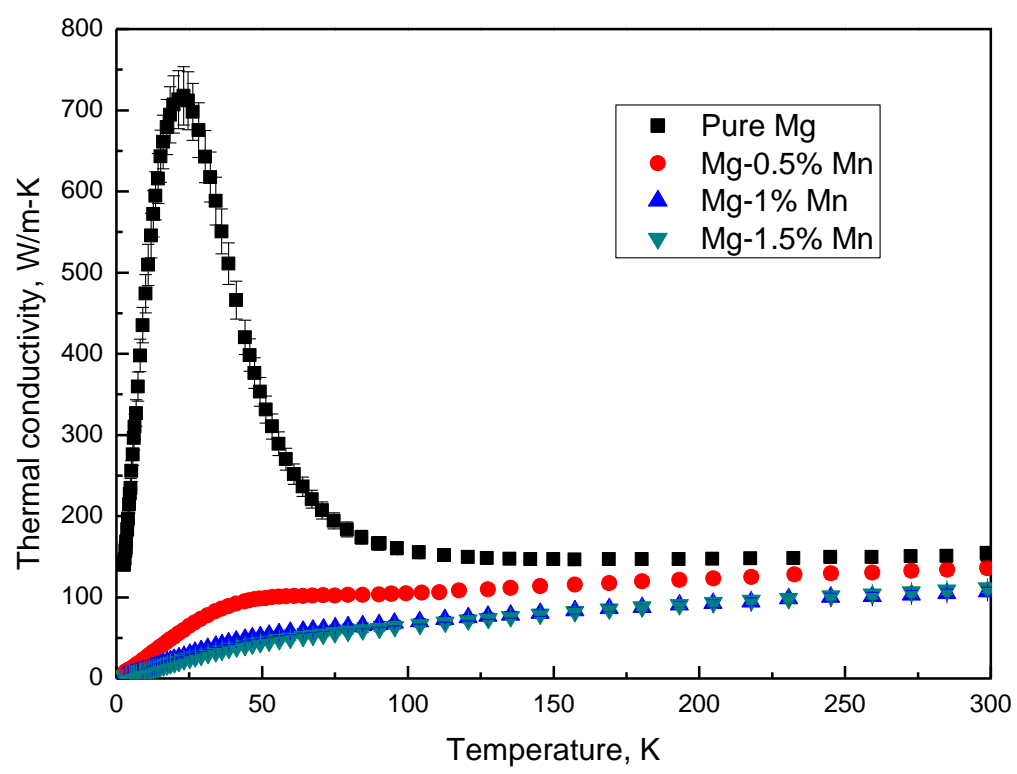

Figure 6: Temperature dependent thermal conductivity of Mg-Mn alloys. 


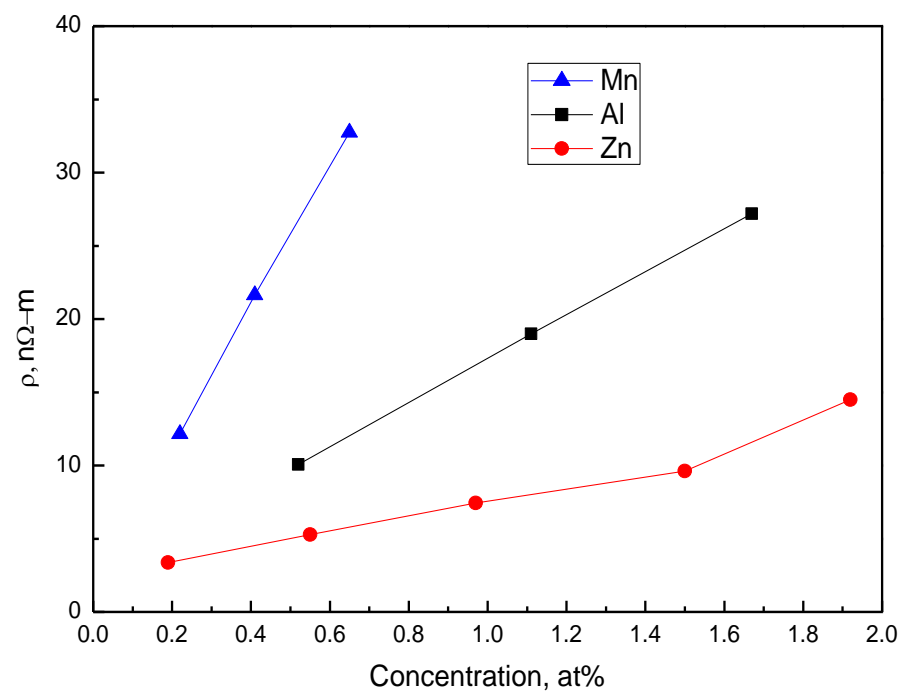

Figure 7: Concentration dependence of residual resistivity of magnesium with $\mathrm{Al}, \mathrm{Zn}$ and $\mathrm{Mn}$ impurities at $5 \mathrm{~K}$.

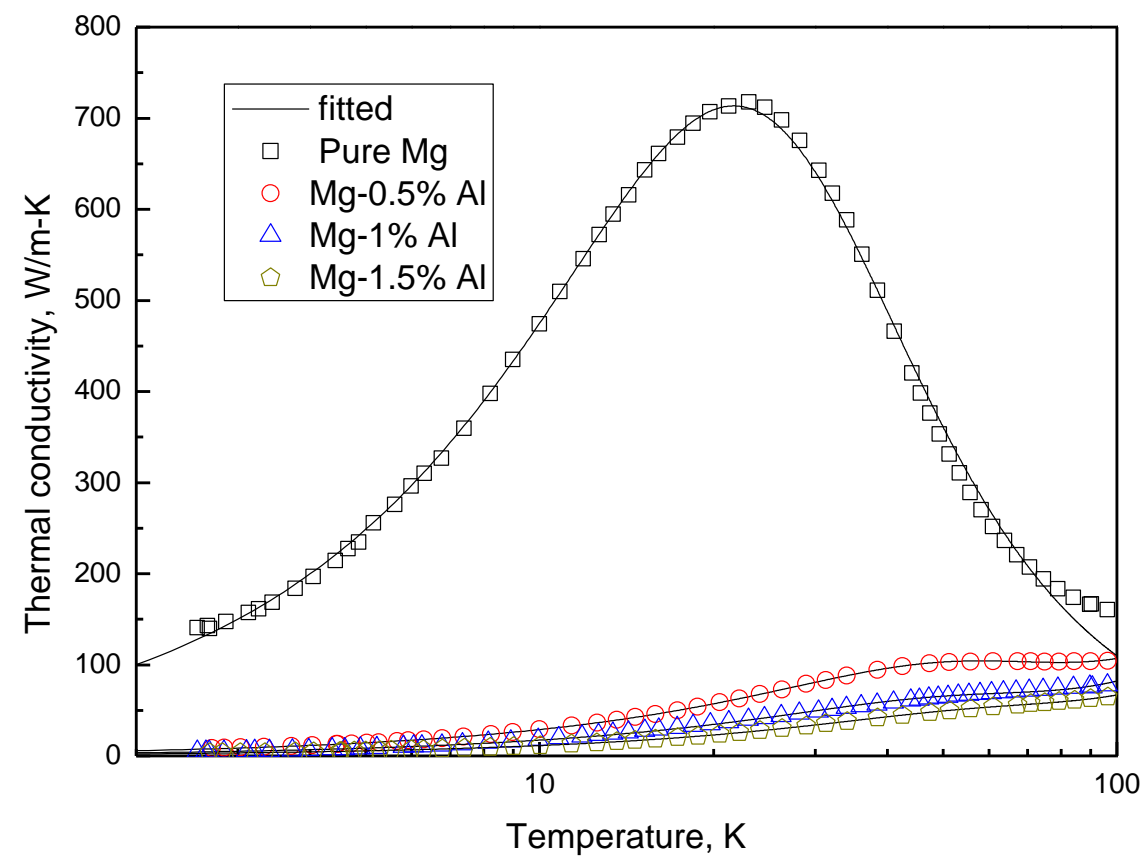

Figure 8: Comparison of fitting results with experimental data of thermal conductivity in pure $\mathrm{Mg}$ and $\mathrm{Mg}-\mathrm{Al}$ alloys. Fitting coefficients are provided in Table 3. 


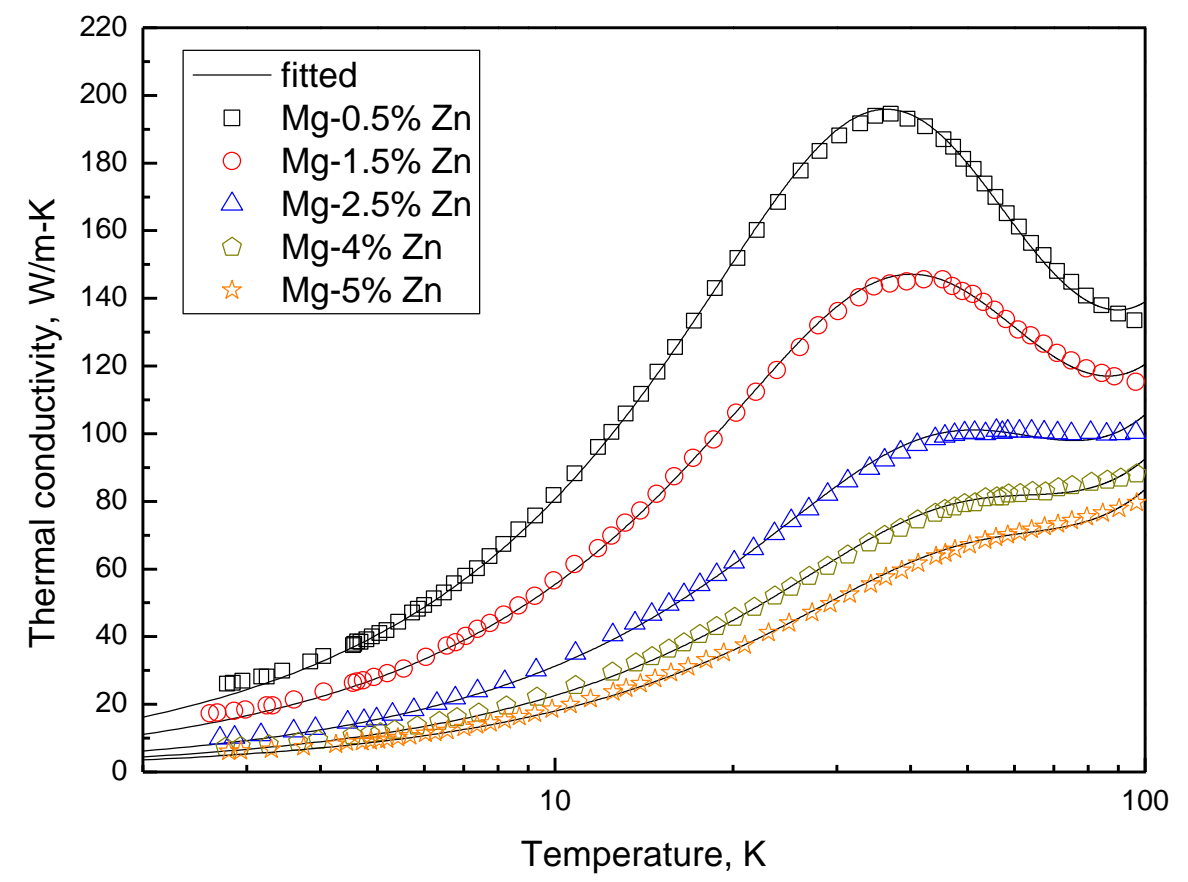

Figure 9: Comparison of fitting results with experimental data of thermal conductivity in Mg-Zn alloys. Fitting parameters are provided in Table 3.

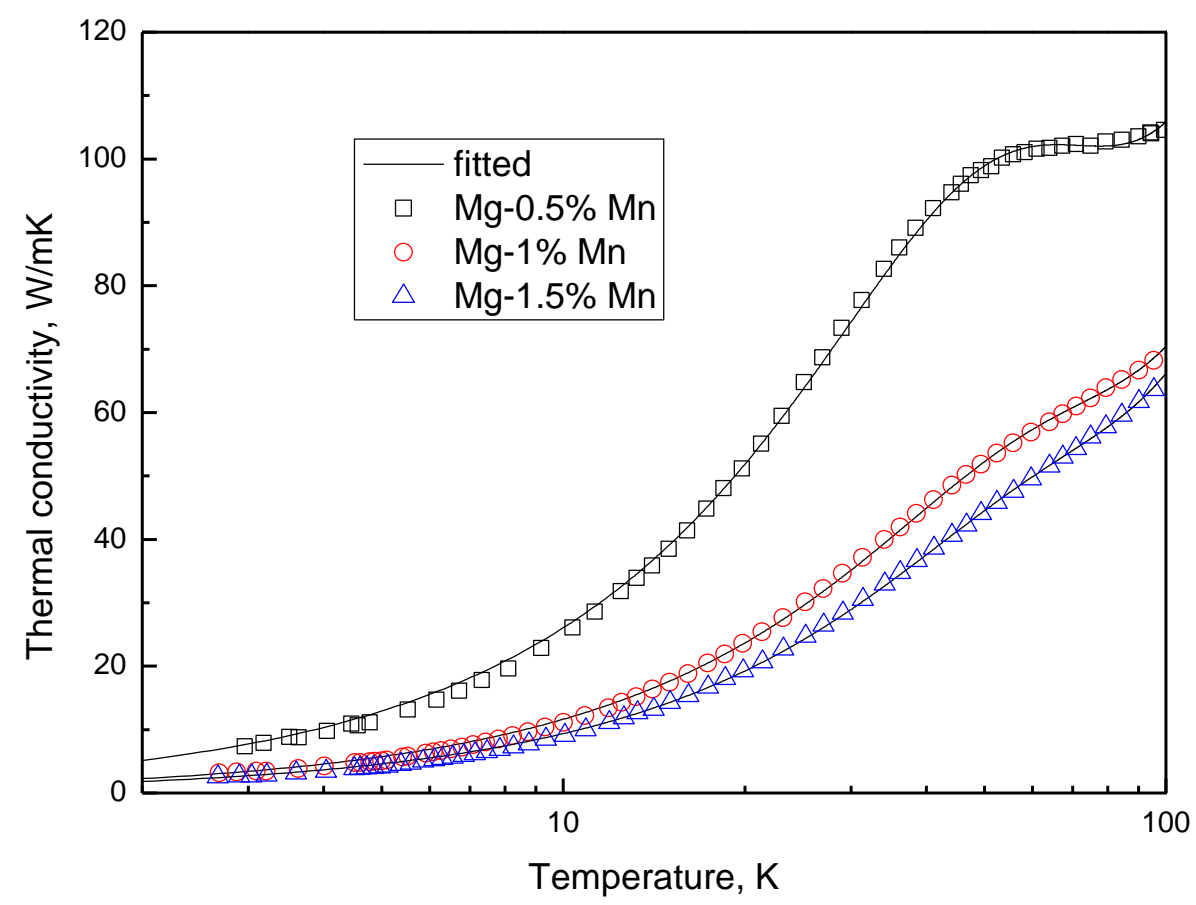

Figure 10: Comparison of fitting results with experimental data of thermal conductivity in Mg-Mn alloys. Fitting parameters are given in Table 3. 

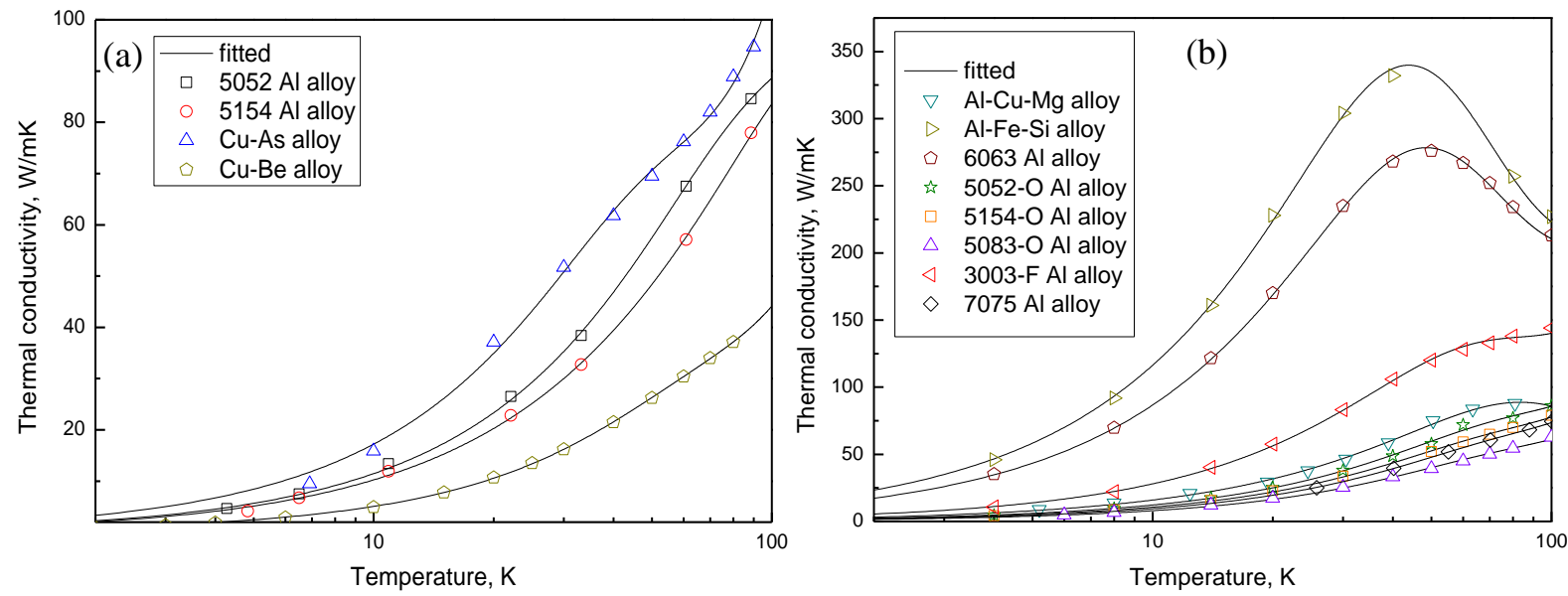

Figure 11: Comparison of fitting results with experimental data of thermal conductivity in (a) binary aluminum and copper alloys and (b) multi-component aluminum alloys. (All experimental data and compositions are from Ref. 23) Fitting parameters are provided in Table 4. 